\title{
Reducing Work Load and Increasing Dimensional Accuracy in Parts for Bending of High-Strength Steel Sheets for Automobiles
}

\author{
Souichiro Nishino ${ }^{1}$ and Kunio Ohya ${ }^{2}$ \\ ${ }^{1}$ Institute of Applied Beam Science, Graduate School of Science and Engineering, Ibaraki University, Hitachi 316-8511, Japan \\ ${ }^{2}$ Ohya Technology Heritage School, Nasushiobara 329-2732, Japan
}

\begin{abstract}
In this paper, we propose a method suitable for increasing the dimensional accuracy in the bending of high-strength steel sheets with a small work load by controlling the amount of a punch indentation in V-bending. The optimal indentation for obtaining the desired bending angle exactly could be calculated by finite-element-method (FEM) simulation using many types of high-strength steel sheets with different material characteristics. This method is effective for reducing the work load and obtaining a small radius of curvature in bent steel sheets; thus, it is suitable for forming high-strength steel sheets, which have been used widely for the fabrication of automobiles.

[doi:10.2320/matertrans.F-M2010828]
\end{abstract}

(Received February 15, 2010; Accepted October 22, 2010; Published February 2, 2011)

Keywords: press working, bending, springback, material, finite element method (FEM), high accuracy, low work load, overbending

\section{Introduction}

In recent years, there has been a need in the automobile industry to both lighten car bodies and improve collision safety, despite the fact that these two demands are contradictory in nature. Resistance to collisions can be improved by reducing the amount of deformation and increasing the amount of energy absorption at the time of a collision. This can be achieved by increasing the cross-sectional size of the vehicle frame and the thicknesses of constituent materials; however, with this approach, an increase in vehicle weight cannot be avoided. One effective means of suppressing this increase in vehicle weight is to use high-strength steel, which shows a high-energy absorption capacity at the time of a collision. The use of high-strength steel can realize a lighter vehicle without increasing costs since it allows the use of existing product design techniques, production technologies, and production facilities. As a result, the use of high-strength steel has been increasing in the fabrication of passenger car bodies that are now available in the market. The highstrength steel that has been used up to now has a tensile strength of up to $590 \mathrm{MPa}$; however, products in a tensile strength range of 780-1180 MPa are now being studied.

At the same time, the widespread use of high-strength steel has given rise to various production problems. To give some background, bending, which is a basic type of pressing, has been widely used in manufacturing plants. However, in the bending of high-strength steel, the amount of springback is larger than that in the bending of mild steel, making it difficult to attain a sufficient processing accuracy. In this regard, there has been much research on predicting the amount of springback by finite-element-method (FEM) simulation. ${ }^{1-5)}$ In a previous report, we proposed a new method for accurately predicting the amount of springback in V-bending by a combination of experiment and FEM simulation used as a hybrid bending technique. ${ }^{6}$ ) However, one major problem that results from giving a sheet metal a high strength is an increase in bending load. In V-bending, it has been reported that the target shape of the bent part is given by pressing in the final step of processing. ${ }^{7)}$ The increase in work load in the pressing of high-strength steel sheets requires a press machine with a large capacity, which necessitates a large facility investment.

To solve the problems that arise at giving automobile sheet metals high strengths, a reevaluation of the bending process must be performed over a wide range of steel types from mild steel to high-strength steel. There have been numerous reports of V-bending of mild steel, aluminum alloys, and stainless steel ${ }^{8-15)}$ however, there have been only few reports on that of high-strength steel. From here on, the application of ultrahigh-strength steel in the $780-1180 \mathrm{MPa}$ range is expected to expand, and to this end, basic data is required. In addition, to achieve an accurate simulation, it is important that a qualitative understanding of phenomena be obtained. In this study, we observed the sheet shaping process for highstrength steel in V-bending in detail and compared the results with those for mild steel. As a result, we discovered a method for shaping steel sheets with a dimensional accuracy and a small work load without having to apply the final stage of pressure bending as in a conventional process. We also proposed a method for predicting optimal process conditions by FEM simulation.

\section{Test Materials and Experimental Method}

To investigate the effects of sheet-metal mechanical properties on the V-bending process, we selected five types of sheet metals differing in tensile strength and hardening type as test materials (Table 1). Steel A is mild steel with a tensile strength grade of $270 \mathrm{MPa}$, while steels B, C, and D have a tensile strength grade of $590 \mathrm{MPa}$. In particular, steel $\mathrm{B}$ is of the high-yield-stress precipitation hardening type, steel $\mathrm{C}$ is of the low-yield-point dual-phase type, and steel D is of the transformation-induced plasticity type (TRIP) with a high ductility. On the other hand, steel $\mathrm{E}$ is a dual-phase high-strength steel with a tensile strength grade of $780 \mathrm{MPa}$. In the experiment, the sheet metal thickness was uniform at $1.4 \mathrm{~mm}$. 
Table 1 Mechanical properties of test materials.

\begin{tabular}{cccccc}
\hline & \multicolumn{2}{c}{ Single Phase } & \multicolumn{3}{c}{ Dual Phase } \\
\cline { 2 - 6 } & A & B & C & D & E \\
& JAC270F & JAC590R & JSC590Y & JSC590T & JSC780Y \\
\hline Thickness of sheet (mm) & 1.4 & 1.4 & 1.4 & 1.4 & 1.4 \\
Yield stress (MPa) & 142 & 476 & 360 & 420 & 448 \\
Tensile stress (MPa) & 292 & 596 & 655 & 610 & 819 \\
Elongation $(\%)$ & 63 & 29 & 31 & 34 & 25 \\
\hline
\end{tabular}

The sheet metals tested here, which are all used for the fabrication of automobiles, include the steel with a $590 \mathrm{MPa}$ high strength grade, which is currently the most widely used steel in the fabrication of car bodies, as well as the steel with a $780 \mathrm{MPa}$ ultrahigh strength grade, which is expected to be used in the future. Test specimens were obtained from sheet metals and given dimensions of $150 \mathrm{~mm}$ in the roll direction and $30 \mathrm{~mm}$ in the orthogonal direction.

The die used in the V-bending experiment is shown in Fig. 1. The bent angle is $90^{\circ}$ and the radius of the punch tip is $R=2$. The radius $R$ of the die tip is less than 2; thus, no load is applied to the bent part. This structure is chosen to differentiate the bending method proposed in this study from the conventional pressure bending method. The material used for the die was quenched and tempered (heat-treated) S45C steel. The experiment was performed using bending dies attached to a press brake with a capacity of $245 \mathrm{kN}$.

In a conventional $\mathrm{V}$-bending experiment, the punch is made to indent the steel sheet as far as the bottom dead center. In this study, however, we let the punch drop but unloaded it before the bottom dead center at a certain amount of punch indentation with the aim of observing the pressing process. Designating the point at which the tip of the punch makes contact with the specimen as the origin, we conducted bending tests with various amounts of indentation. We also performed pressure bending at the bottom dead center at pressures of 20 and $50 \mathrm{kN}$. Examples of results for different amounts of indentation are shown in Fig. 2. After each test,

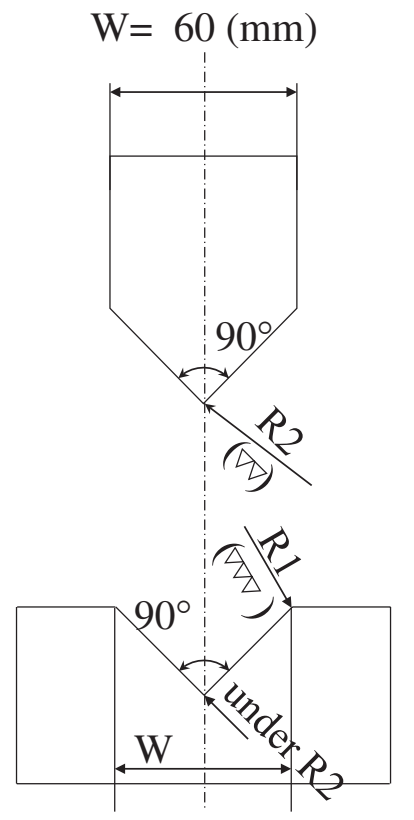

Fig. 1 Geometries of punch and die.

we measured the bent angle of each specimen. The bent angle is defined, as shown in Fig. 3.

\section{Experimental Results}

The relationship between the bent angle and the amount of indentation obtained by the V-bending tests is shown in Fig. 4 for each type of material. As can be seen from the figure, the bent angle approaches $90^{\circ}$ (angle of die) as the amount of punch indentation increases and reaches $90^{\circ}$ at a certain amount of indentation for all materials. It can also be observed here that the bent angle decreases to less than $90^{\circ}$ as the amount of indentation further increases, resulting in a shape smaller than the die angle. The test materials were also pressed to the bottom dead center, again resulting in bent angles near $90^{\circ}$. However, the bent angle obtained by this

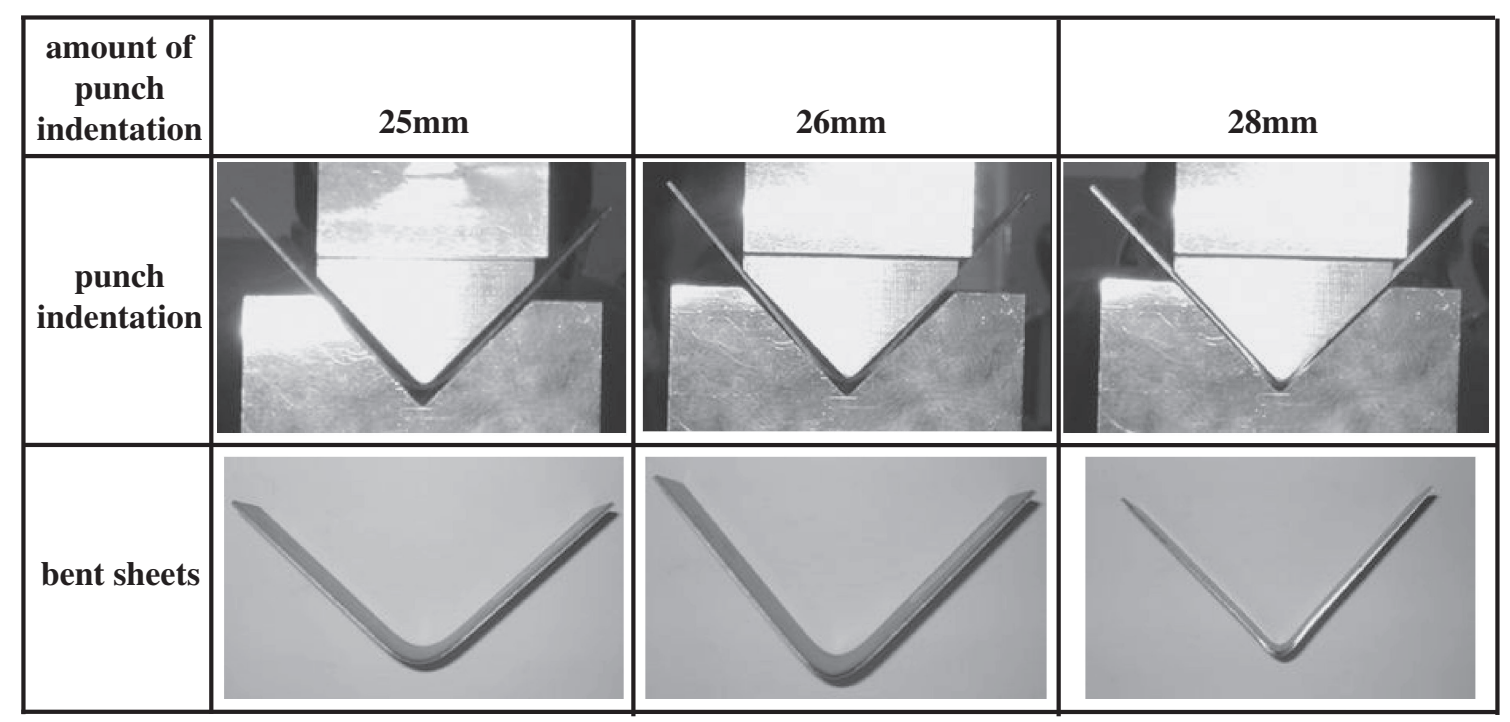

Fig. 2 V-bending process and sectional shape of bent specimen (JAC270F). 


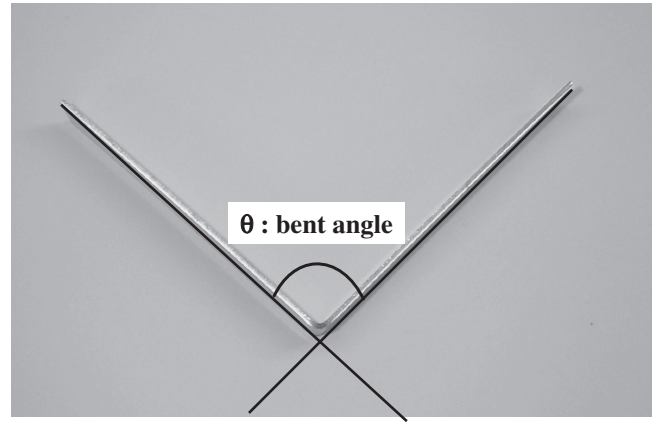

Fig. 3 Bent angle of specimen (JAC270F).

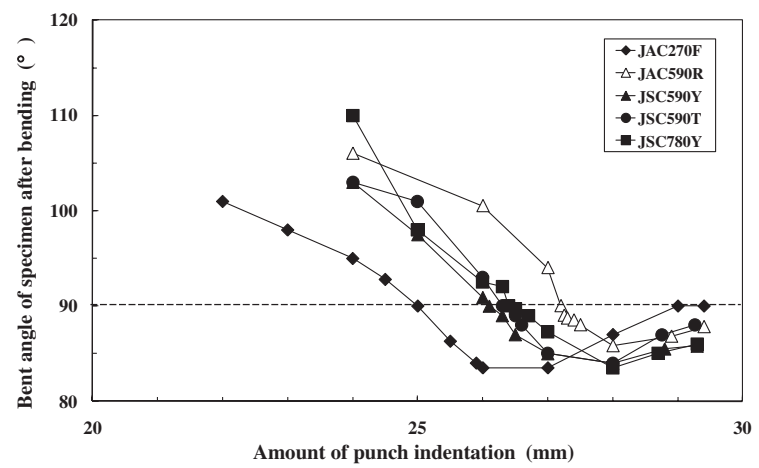

Fig. 4 Bent angle after V-bending vs punch indentation.

pressure bending process in the case of high-strength steel does not stay fixed at $90^{\circ}$ as in the case of mild steel. The amount of indentation at a bent angle of $90^{\circ}$ is defined as the "optimal amount of indentation", which varies according to the type of material used. A further increase in the amount of indentation results in a bent angle less than $90^{\circ}$ in all materials. Moreover, when performing pressure bending at the bottom dead center, the bent angle differs between mild steel, high-strength steel, and ultrahigh-strength steel. In the pressure bending of mild steel (steel A), the bent angle of the specimen is $90^{\circ}$; however, in that of high-strength steel or ultrahigh-strength steel (steels B-E), the bent angle is other than $90^{\circ}$. In the cases of high-strength steel and ultrahighstrength steel, it is difficult to maintain the shape by pressure bending.

\section{Discussion}

\subsection{Process observation}

To clarify the sheet formation process, we analyzed the photographs of the process in detail. Figure 5 depicts the sheet forming process in the V-bending of mild steel and high-strength steel. The bending advances through four stages, that is, (a) three-point bending, (b) overbending, (c) unbending, and (d) pressure bending, in turn. ${ }^{7)}$ In stage (b), the material bends beyond $90^{\circ}$ (Fig. 6). After loading, springback occurs, and the bent angle returns to $90^{\circ}$. Figure 7 shows the bent angle versus the amount of indentation in mild steel and high-strength steel. The broken line shows the bent angle on loading and the solid line the shape after loading. As can be seen, overbending occurs regardless of material

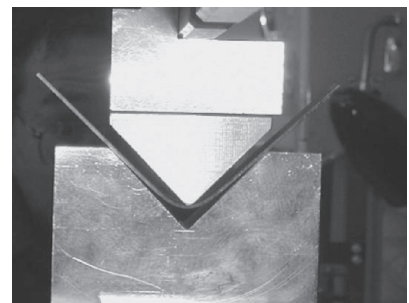

(a) : three points bending

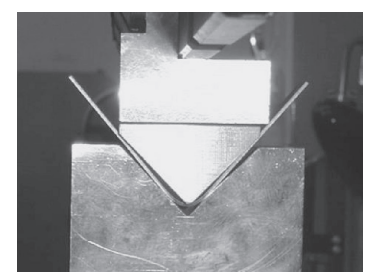

(b) : over-bending

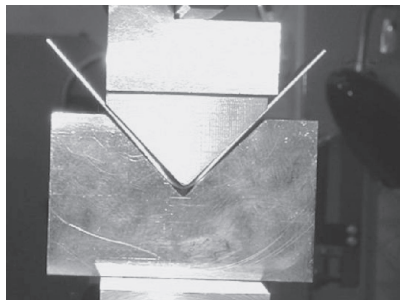

(c) : unbending

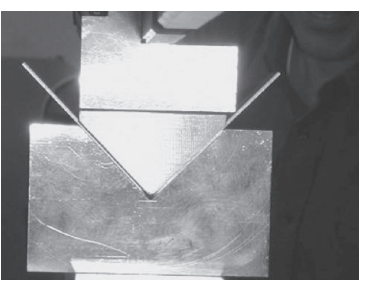

(d) : pressure bending
Fig. 5 V-bending process (A: JAC270F).
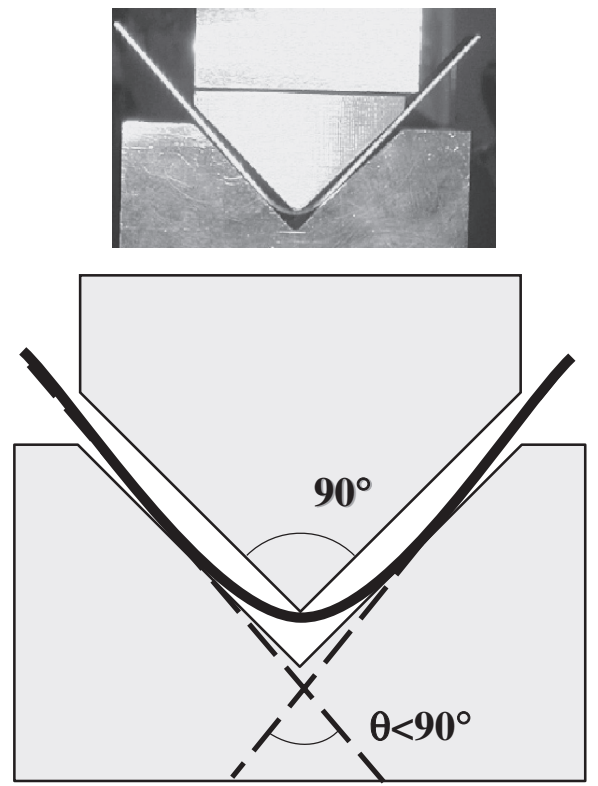

Fig. 6 Overbending.

strength, and the bent angle returns to the target angle of $90^{\circ}$ owing to springback after loading. After stage (b), unbending occurs. Here, the specimen is bent in the opposite direction at the flange section, resulting in a bent angle of less than $90^{\circ}$. Unbending is a phenomenon different from overbending. Next, for mild steel, the bent angle again approaches $90^{\circ}$ owing to pressure bending. However, for high-strength steel, a bent angle of less than $90^{\circ}$ cannot be corrected even with pressure bending.

Figure 8 shows the cross-sectional shapes of bent parts between mild steel (A) and high-strength steel (E) for the same amount of indentation $(25 \mathrm{~mm})$. These results show that the bending shape differs according to material characteristics. The mild steel exhibits a significant sheet bending and a large amount of overbending, while high-strength steel exhibits a small amount of overbending. Thus, the amount of indentation for achieving a bent angle of $90^{\circ}$ increases with 

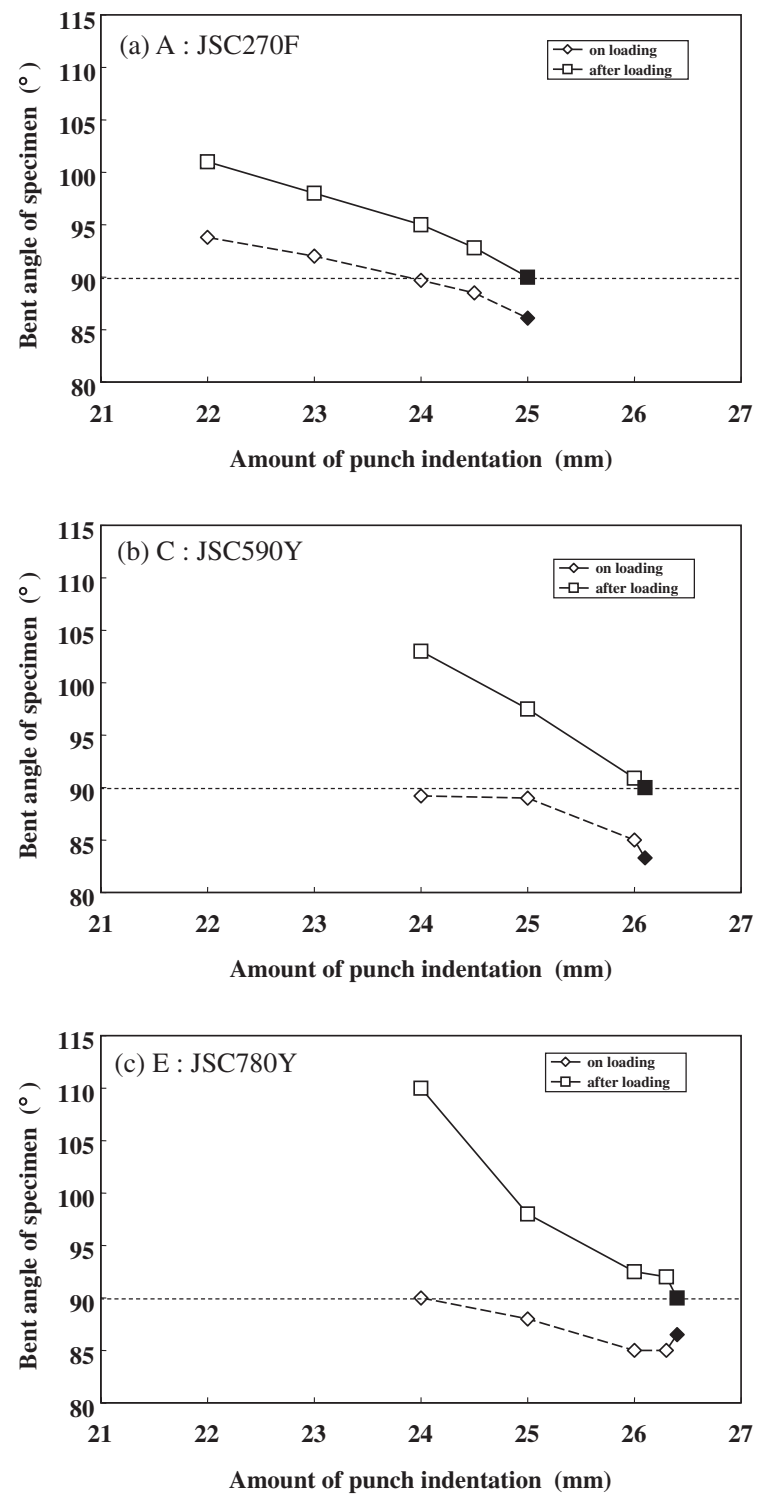

Fig. 7 Bent angles of specimen on loading and after loading.

the strength of the material. In addition, the optimal amount of indentation differs according to material properties even for high-strength steels of the same $590 \mathrm{MPa}$ tensile strength grade. The DP-type steel shows a large amount of overbending owing to a low yield point, and its optimal amount of indentation is smaller than that of the deposited steel.

The pressing method proposed in this study enables the bending of high-strength steel with a small bending load. As shown in Fig. 9, the amount of bending deformation is smaller for high-strength steel, indicating that type-780 highstrength steel is formed with a smaller radius of curvature $R$ than mild steel. Forming high-strength steel with a small radius of curvature using a conventional pressure bending process is difficult owing to the need for a high work load.

\subsection{Measurement of bending load}

To investigate the bending load for various amounts of indentation, we performed measurements using an Instrontype universal tensile testing machine, as shown in Fig. 10. Specifically, we placed the bending die on the testing
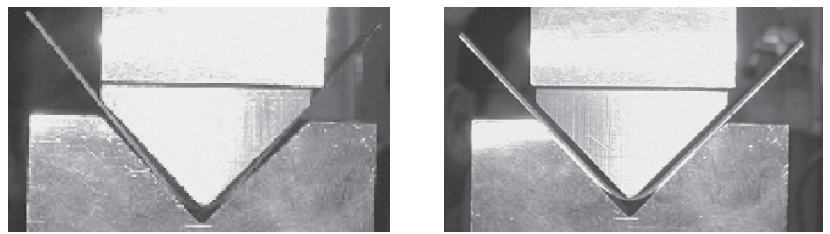

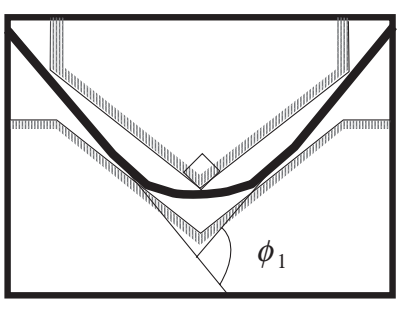

A : JAC270F

$$
\phi_{1}>\phi_{2}
$$

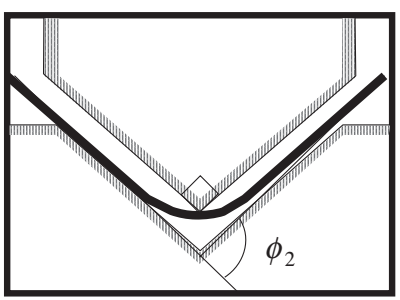

E : JSC780Y

Fig. 8 Difference in overbending between mild steel and high-strength steels (amounts of punch indentation of steels A and E are 25 and $26.4 \mathrm{~mm}$, respectively).

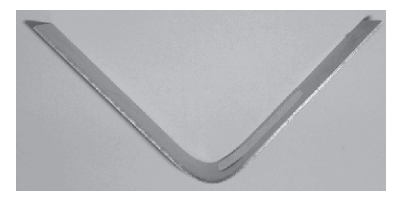

A : JAC270F

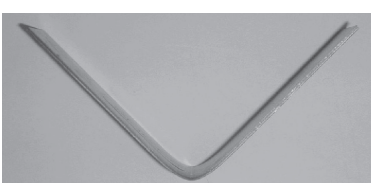

E : JSC780Y
Fig. 9 Difference in curvature radius between mild steel and high-strength steel.

machine and performed sheet-shaping tests to investigate the press work load.

Measurement results for steels $\mathrm{A}, \mathrm{C}$, and $\mathrm{E}$ are shown in Fig. 11. The curves in the figure represent the work load versus the amount of indentation, and marks indicate the work load at a bent angle of $90^{\circ}$. These results show that a bent angle of $90^{\circ}$ can be formed at a very small work load. Next, the relationship between the optimal amount of indentation (corresponding to a bent angle of $90^{\circ}$ ) and the work load is shown in Fig. 12. Note here that the bent angle of $90^{\circ}$ in Figs. 11 and 12 refers to the angle after unloading. These results show that the work load and the amount of indentation vary according to the type of test material used. They also show that the work load required is very small.

\subsection{Simulation of optimal amount of indentation}

We next performed FEM simulations under the same conditions as the experiment described above. In these simulations, calculations were performed by an updated Lagrangian method using MSC-MARC, a general-purpose elasto-plasticity-analysis software package. The updated Lagrangian method considers time $t$ in the deformation process to be the reference configuration and calculates the configuration at time $t+\Delta t$, where $\Delta t$ is a finite but very small increment in time (step interval). This configuration at time $t+\Delta t$ is now considered to be the new reference configuration. In this manner, the reference configuration is updated in every calculation step. The material constants used in these FEM simulations were obtained by inputting the 


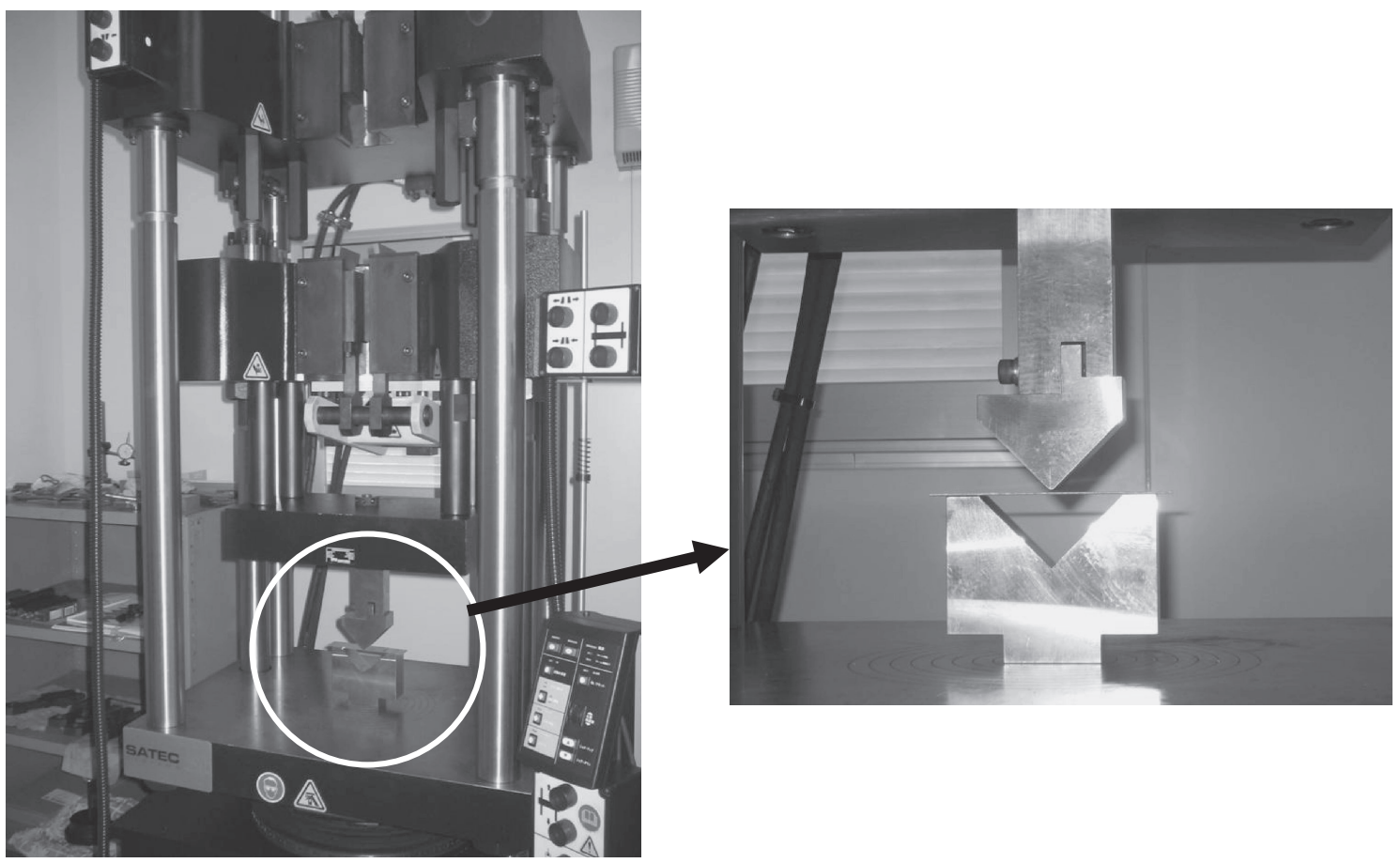

Fig. 10 Measurement of bending load.

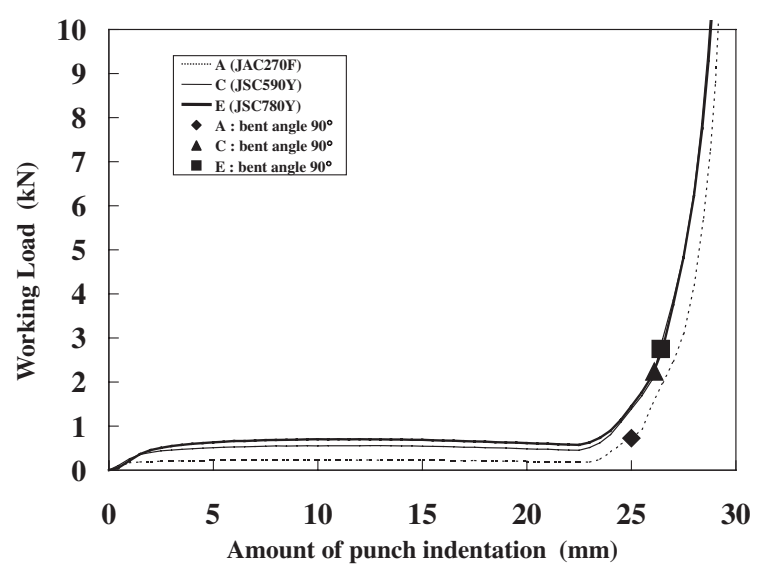

Fig. 11 Work load curves during punch indentation.

stress-strain curves for each test material. Figure 13 shows the analysis model and meshing employed. Figure 14 shows the results of computing the optimal amount of indentation by FEM analysis.

On examining these results, it can be seen that simulation results are in good agreement with experimental results, demonstrating that the optimal amount of indentation can be predicted by simulation. Figure 15 shows the experimental and simulation results for the optimal amount of indentation. As shown, the experimental and simulation results again show good agreement. However, for indentations greater than the optimal amount of indentation, experimental and simulation results do not agree, as sown in Fig. 14. As shown by the photographs in Fig. 5, unbending (reverse bending) occurs as the bending process proceeds, suggesting that accurate analysis results cannot be obtained without considering the Bauschinger effect. However, as the optimal amount of indentation proposed in this study is determined

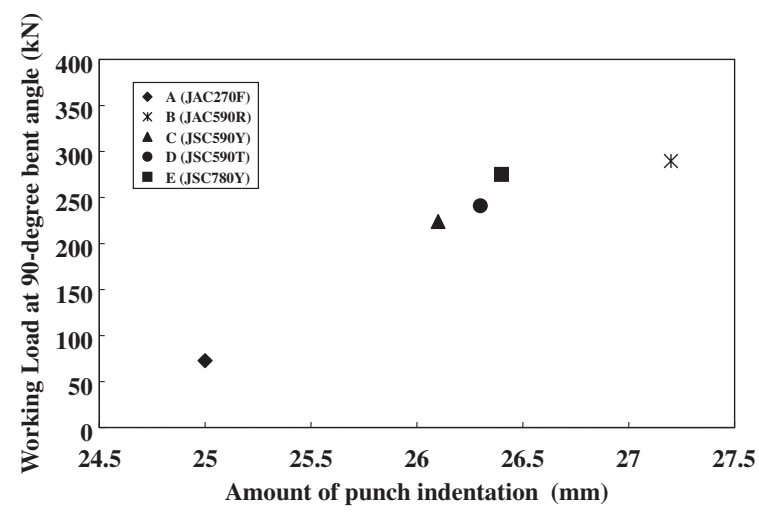

Fig. 12 Work load vs punch indentation at bent angle of $90^{\circ}$.

before the onset of unbending, it is still possible to make high-accuracy predictions by simulation without having to consider complex material characteristics at the time of unbending.

\section{Conclusions}

In this study, we performed a V-bending experiment using various types of sheet metal for automobile use from mild steel to ultrahigh-strength steel and observed the sheet shaping process in detail. We discovered that the target bent angle $\left(90^{\circ}\right.$ in this study) could be obtained at a stage prior to pressure bending. A detailed study of this point revealed the following results indicating that the bending accuracy of high-strength steel can be improved and that the bending load can be reduced.

(1) In the bending of sheet metals, the target bent angle can be achieved at a low work load without pressure bending by controlling the amount of indentation. 


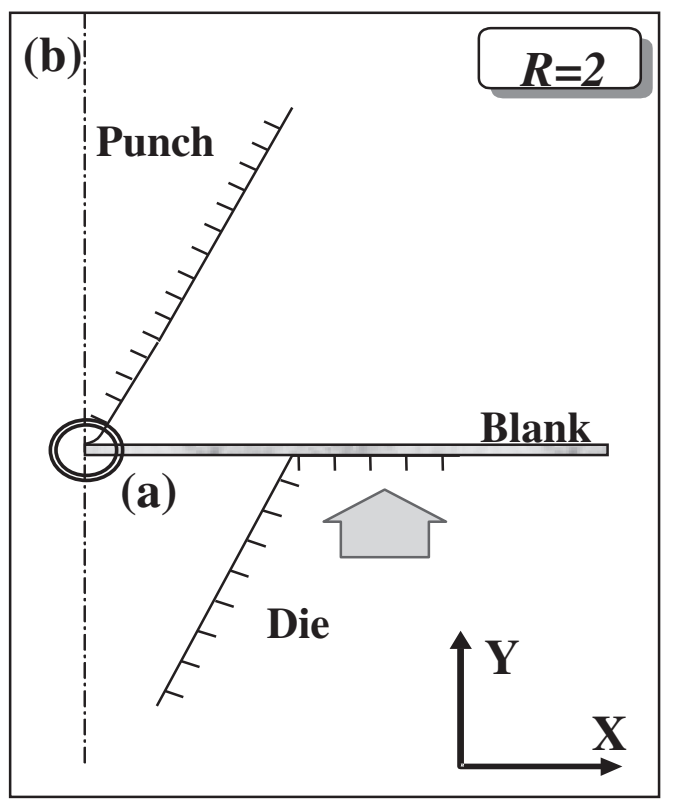

\section{(a) Arbitrary 4-node Quadrilateral ring element \\ (b) Center line}

Number of Elements : 600

Number of Nodes : 755

Fig. 13 Analysis model and meshing in FEM simulation.

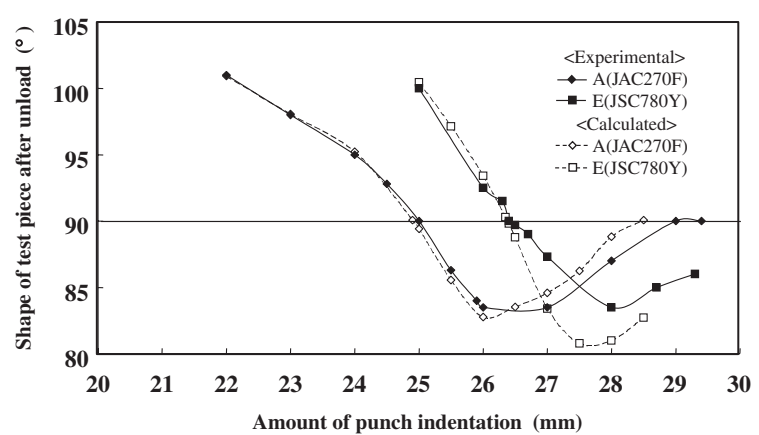

Fig. 14 Comparison of calculated data with experimental data on the relationship between bent angle of specimen after unloading and amount of punch indentation.

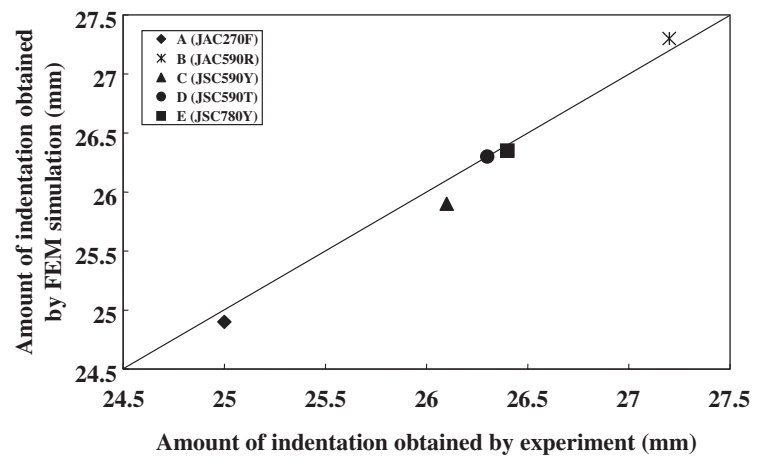

Fig. 15 Comparison of FEM simulation data with experimental data on $90^{\circ}$-bent-angle indentation.

(2) The overbending phenomenon caused by material deformation results in steel-sheet bending beyond the target bent angle, but springback after unloading results in a return to the target angle in a region of small punch indentation and low working load.

(3) The amount of indentation for achieving the target bent angle can be computed by FEM simulation using the characteristics of the test materials.

(4) The bending-shaping method considered in this study reduces the press work load and realizes a small radius of curvature in high-strength steel.

\section{REFERENCES}

1) W. N. Chan, H. I. Chew, H. P. Lee and B. T. Cheok: J. Mater. Process. Technol. 148 (2004) 15-24.

2) X. Li, Y. Yang, Y. Wang, J. Bao and S. Li: J. Mater. Process. Technol. 123 (2002) 209-211.

3) A. Forcellese, L. Fratini, F. Gabrielli and F. Micari: J. Mater. Process. Technol. 80-81 (1998) 108-112.

4) A. Nilsson, L. Melin and C. Magnusson: J. Mater. Process. Technol. 65 (1997) 52-58.

5) A. Forcellese, L. Fratini, F. Gabrielli and F. Micari: J. Mater. Process. Technol. 60 (1996) 225-232.

6) S. Nishino, K. Ohya and K. Naruishi: JSAE Rev. 24 (2003) 283-288.

7) M. Masuda: Usuita-no-Magekakoh, (Seibundoh-Shinkohsha, 1958) pp. 136-179.

8) Z. Tekiner: J. Mater. Process. Technol. 145 (2004) 109-117.

9) M. V. Inamdar, P. P. Date and S. V. Sabnis: J. Mater. Process. Technol. 123 (2002) 459-463.

10) N. Asnafi: J. Mater. Process. Technol. 21 (2000) 217-236.

11) K. L. Elkins and R. H. Sturges: J. Manuf. Sci. Eng. ASME 121 (1999) 679-688.

12) I. C. Zhang, G. Lu and S. C. Leong: J. Mater. Process. Technol. 63 (1997) 134-139.

13) F. Pourboghrat and K. A. Stelson: J. Manuf. Sci. Eng. ASME 119 (1997) 227-237.

14) S. K. Kwok and W. B. Lee: J. Mater. Process. Technol. 48 (1995) 4349.

15) Z. Tan, B. Persson and C. Magnusson: J. Mater. Process. Technol. 34 (1992) 449-455. 